\title{
Morel-Lavallée Lesion: A Study of Three Cases
}

\author{
Seema Mittal ${ }^{1}$, Tejinder S Dall ${ }^{2}$, Raman Mittal ${ }^{3}$
}

\begin{abstract}
Background: Morel-Lavallée lesion is a rare clinical presentation which involves detachment of skin and subcutaneous fat from underlying fixed fascia which mainly occurs after traumatic injury. Morel-Lavallée lesions require immediate attention because it may lead to superinfection and poor patient outcomes, if treatment is delayed.

Materials and methods: A detailed case study was done of three patients who were diagnosed with Morel-Lavallée lesion at the outpatient surgery department of tertiary care center at Amritsar.

Results and conclusion: Patients were treated either surgically or conservatively and they responded to treatment. It can be concluded that the initial treatment is critical to shortening the clinical course and preventing the recurrence. Early diagnosis and management are essential. The Morel-Lavallée lesion is usually missed during the initial assessment, so a thorough clinical examination of roadside accident should be done to rule out such lesions. Neglected lesions can become infected and progression of lesion may lead to extensive skin necrosis.

Keywords: Degloving, Morel-Lavallée lesion, Soft tissue injury.

AMEl's Current Trends in Diagnosis \& Treatment (2019): 10.5005/jp-journals-10055-0071
\end{abstract}

\section{INTRODUCTION}

Morel-Lavallée lesion, also called as the closed degloving injury, is a rare clinical presentation which requires early diagnosis for better prognosis. These lesions require early diagnosis because they are slow to develop and may clinically be misdiagnosed as a soft tissue tumor. A report of three cases is being presented.

Morel effusions are a rare finding and its detailed account for the first time was given by The French Physician Maurice Morel-Lavallee. Later on Letournel and Judet described the degloving injuries that occurred over the greater trochanter region as Morel-Lavallée lesions. ${ }^{1,2}$ This injury occurs due to the experience of a tangential force to the skin surface resulting in the detachment of skin and subcutaneous fat from more fixed underlying fascia. ${ }^{3}$ A cavity is created by this separation, which gets filled with hematoma. Hematoma results due to the disruption of arteries that perforate the fascia. Virtual cavity, thus formed, gets filled with blood, lymph, and debris. ${ }^{2}$ These lesions have been registered under diverse names, which includes pseudocyst, posttraumatic cyst of soft tissue, Morel-Lavallee effusion, and Morel-Lavallee extravasation. ${ }^{4}$ These lesions originate due to traumatic injury but in one third of the cases traumatic injury may be absent. Clinically the lesion usually presents as swelling or fluctuant area over the skin, which may grow in size, decrease in size, or remain stable. These lesions may be accompanied by necrosis and infection of the overlying skin. In some cases, these lesions may go unnoticed and detected only after months or years of traumatic history. ${ }^{5}$ The most common site involved is the thigh over the greater trochanter, but abdominal wall, lower lumbar, spine buttocks, and regions of the scapula may also encounter such lesions. The trochanteric region is the most sensitive or vulnerable because of the rich blood supply in this region along with fixed fascia and relatively mobile overlying skin. ${ }^{5}$

\section{Case Descriptions}

\section{Case 1}

A 43-year-old male presented with a chief complaint of necrotic tissue on proximal part of the left lateral thigh and swelling on the

\footnotetext{
1,2 Department of Surgery, Sri Guru Ram Das Institute of Medical Sciences and Research, Amritsar, Punjab, India

${ }^{3}$ I PLAST, Amritsar, Punjab, India

Corresponding Author: Tejinder S Dall, Department of Surgery, Sri Guru Ram Das Institute of Medical Sciences and Research, Amritsar, Punjab, India, Phone: +91 9478028808, e-mail: drtejindersinghdall@ gmail.com
}

How to cite this article: Mittal S, Dall TS, Mittal R. Morel-Lavallée Lesion: A Study of Three Cases. AMEl's Curr Trends Diagn Treat 2019;3(2): 79-81.

Source of support: Nil

Conflict of interest: None

lateral aspect of the left thigh (as shown in Fig. 1A) after roadside accident. The patient met with roadside accident about 2 weeks from presentation. Swelling developed few days after roadside accident. Initially the patient got treated for this swelling at one private nursing home where magnetic resonance imaging (MRI) of the left thigh was done, which showed a well-circumscribed subcutaneous collection (Fig. 1B) of low T1 signal and increased short tau inversion recovery (STIR) signal superficial to the tensor fascia lata, vastus lateralis, rectus femoris, vastus medialis, semimembranosus, and biceps femoris muscles, containing a lobule of internal fat signal. The MRI of the left thigh showed a well-circumscribed subcutaneous collection of $1.5 \times 8.3 \times 30.5 \mathrm{~cm}$ [anteroposterior $(\mathrm{AP}) \times$ transvers $(\mathrm{TR}) \times$ craniocaudal $(\mathrm{CC})]$ suggestive of Morel-Lavallée lesion. Patient was treated at a private nursing home where a small incision was made on the swelling and the fluid was aspirated followed by the application of compression bandages. The same was repeated daily for about a week, but the patient did not respond to treatment and was referred to an advanced center. When the patient was presented to the outpatient department (OPD) of tertiary care center at Amritsar, about $1 \mathrm{~L}$ of fluid was aspirated from the already made incision, free flow of fluid was observed, and swelling subsided to some extent initially but occurred again after 2 days. Later on the wound was explored in the operation theater, pseudocapsule found as shown 

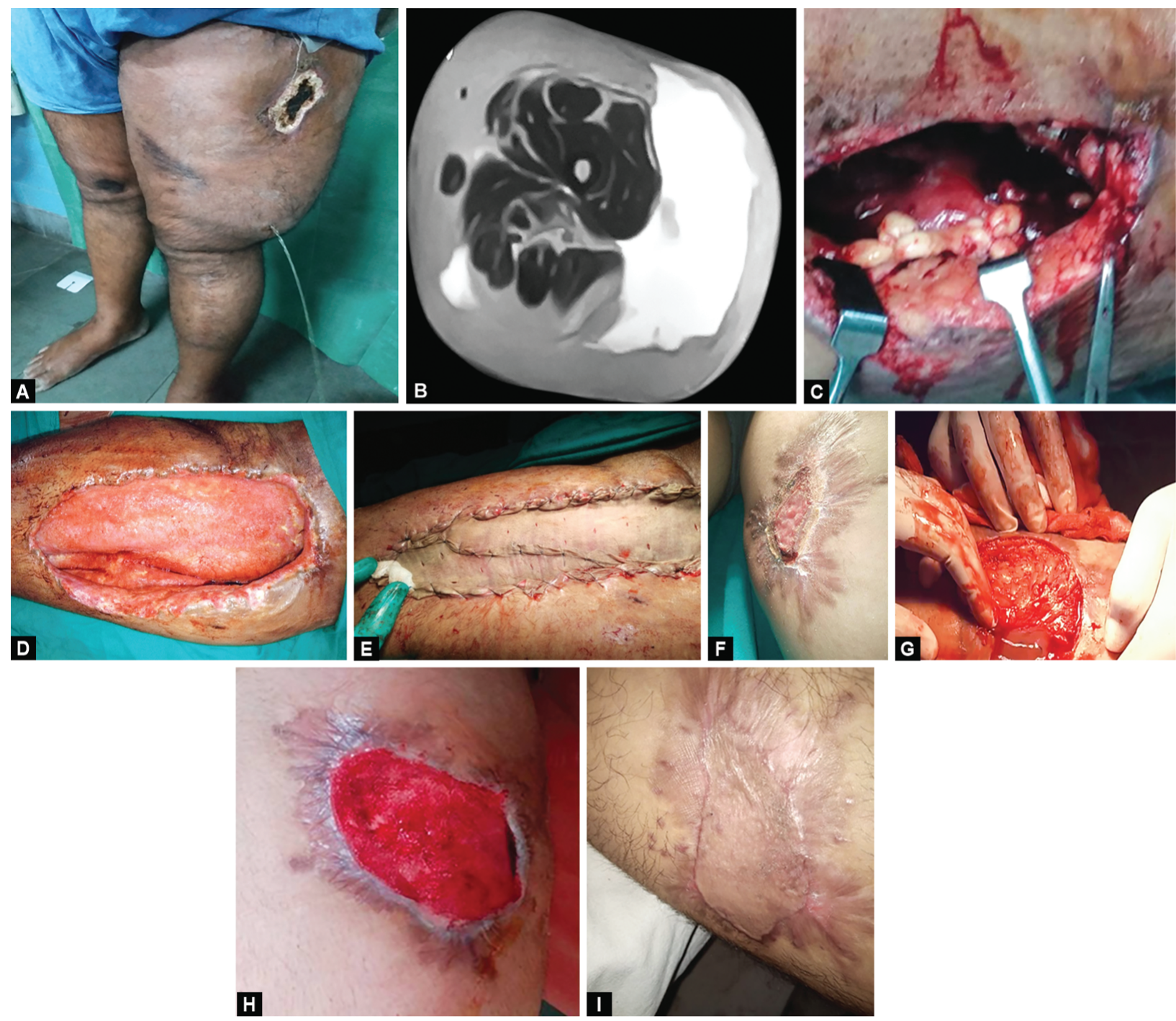

Figs 1 A to G: (A) Clinical picture shows free flow of fluid from the swelling; (B) Magnetic resonance imaging of left thigh showing fluid collection; (C) Intraoperatively showing pseudocapsule formation; (D) Wound after vacuum-assisted closure dressing; (E) Intraoperatively after split skin grafting; (F) Preoperative wound presentation; (G) Intraoperative pus drainage; (H) Pus drainage obliteration after VAC dressing; (I) Postoperative after split skin grafting

in Figure $1 C$, excised, and closure done in layers. Later the wound was managed by vacuum-assisted closure (VAC) dressing (Fig. 1D); sclerodesis, and split skin grafting (Fig. 1E) were also done. Patient responded to treatment.

\section{Case 2}

A 19-year-old male patient in the OPD presented with an alleged history of roadside accident with a wound on the medial side of the left mid-thigh. It was associated with a small wound on the lateral aspect of the middle one third of the left thigh, and there was also a fluctuant swelling between two wounds as evident in Figure 1F. Patient was getting regular dressings for the same from some private hospital but was not relieved. It was explored in the operation theater and was found to be a pus filled cavity communicating with the wound regions. About $1 \mathrm{~L}$ pus was drained (Fig. 1G) and sent for culture sensitivity. Aseptic dressing was done with the betadine-soaked role gauge for a week and later on a VAC dressing was done. The cavity so formed after pus drainage became shallow after the first VAC dressing and was obliterated after second VAC dressing as evident in Figure 1H. Later on split skin grafting was done (Fig. 11). The patient responded well to treatment and recovered.

\section{Case 3}

A 43-year-old male patient came with an alleged history of roadside accident with maxillofacial trauma and closed degloving injury on the left thigh. Multiple aspirations of $500 \mathrm{~mL}$ to $1 \mathrm{~L}$ fluid were followed by compression bandages. Patient responded to the treatment and recovered.

\section{Discussion}

Clinically, this case study is important because Morel-Lavallée lesions are rare. Healthcare professionals involved in emergency services are not very much familiar with the Morel-Lavallée lesions. ${ }^{6}$ Morel-Lavallée lesions are most commonly encountered over the lateral trochanter and proximal thigh, and this region is most vulnerable due to good vascular supply; but the slow development of these lesions makes the clinical diagnosis a cumbersome task. 
In the acute traumatic injuries, these lesions should be managed by surgical intervention to prohibit infection. ${ }^{7}$ Therefore, diagnosis at early stages of degloving soft tissue injuries poses a challenge for clinicians. Sometimes these lesions may become large enough to be misdiagnosed as a tumor of soft tissue. ${ }^{2}$ Sometimes peripheral capsule formed due to inflammatory reaction may lead to perpetuation of the lesion. 1,7,8 Therefore, early diagnosis of MorelLavallée lesions are very much crucial for prognosis. The main modality of diagnosis are ultrasonography, MRI, and computed tomography. ${ }^{9}$ Ultrasound-guided aspiration and local compression may be the treatment modalities for these lesions. ${ }^{2}$ Other treatment modalities may include debridement followed by skin grafts, free tissue transfer, and revascularization. ${ }^{10}$ Advanced technique for the management of closed degloving injuries is VAC. ${ }^{10}$

\section{Conclusion}

It can be concluded that the initial treatment is critical to shortening the clinical course and preventing the recurrence. The MorelLavallée lesion is usually missed during the initial assessment so a thorough clinical examination with roadside accident should be done to rule out such lesions. Neglected lesions can become infected and progression of lesion may lead to extensive skin necrosis. ${ }^{11}$ Early diagnosis and management are essential.

\section{References}

1. Letournel E, Judet R. Fractures of the acetabulum. 2nd ed., Berlin, Germany: Springer-Verlag; 1993.
2. McNally E. Practical musculosketal ultrasound. 2nd ed., Oxford: Elsevier; 2014.

3. Jowett $C$, May J, Myers $S$, et al. Open fractures and associated soft tissue injuries. In: Sebastian DB, Pramod A, Timothy B, et al. Orthopedic Trauma: The Stanmore and Royal London Guide. New York: Taylor Francis; 2015. pp. 3-26.

4. Evans RC. Illustrated Orthopedic Physical Assesment. USA: Mosby Elsevier; 2009.

5. Boe J. Morel lavallee lesions. In: Daldrup-link HE, Newman B. Pearls and Pitfalls in Pediatric Imaging: Variants and Other Difficult Diagnosis. UK: Cambridge University Press; 2014. pp. 380-383.

6. Myrick KM, Davis S. Morel Lavallee injury a case study. Clin case rep[Internet] 2018;6(6):1033-1039. DOI: 10.1002\%2Fccr3.1518.

7. Hak DJ, Olson SA, Matta JM. Diagnosis and management of closed internal degloving injuries associated with pelvic and acetabular fractures: the morel-lavallée lesion. J Trauma [Internet] 1997;42(6):1046-1051. DOI: 10.1097/00005373-199706000-00010.

8. Parra JA, Fernandez MA, Encinas B, et al. Morel-lavallée effusions in the thigh. Skeletal Radiol [Internet] 1997;26(4):239-241. Available from: $10.1007 / \mathrm{s} 002560050228$.

9. Latifi R. The diagnostic and therapeutic challenges of degloving softtissue injuries. SOJ Surgery [Internet] 2013;1(3):01. DOI: 10.4103/09742700.136870

10. Hakim S, Ahmed K, El-Menyar A, et al. Patterns and management of degloving injuries: a single national level 1 trauma center experience. World J Emerg Surg [Internet] 2016;11(1):1. Available from: 10.1186/ s13017-016-0093-2.

11. Nair A, Nazar P, Sekhar R, et al. Morel-Lavallée lesion: a closed degloving injury that requires real attention. Indian J Radiol Imaging [Internet] 2014;24(3):288. DOI: 10.4103/0971-3026.137053.Available from: http://www.ijri.org/text.asp?2014/24/3/288/137053. 